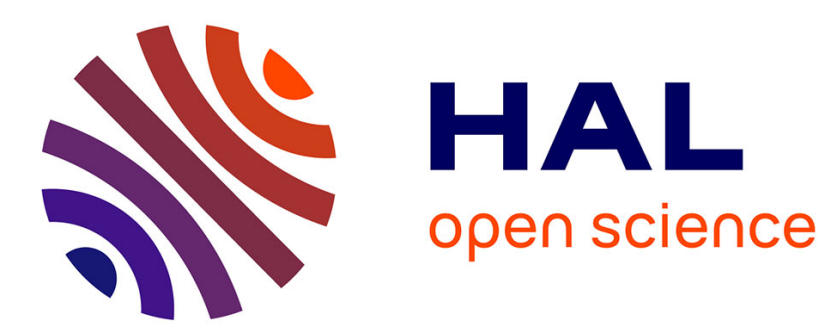

\title{
Differences in the resource intake of two sympatric Australian stingless bee species
}

\author{
Sara Leonhardt, Tim Heard, Helen Wallace
}

\section{To cite this version:}

Sara Leonhardt, Tim Heard, Helen Wallace. Differences in the resource intake of two sympatric Australian stingless bee species. Apidologie, 2014, 45 (4), pp.514-527. 10.1007/s13592-013-0266-x . hal-01234745

\section{HAL Id: hal-01234745 \\ https://hal.science/hal-01234745}

Submitted on 27 Nov 2015

HAL is a multi-disciplinary open access archive for the deposit and dissemination of scientific research documents, whether they are published or not. The documents may come from teaching and research institutions in France or abroad, or from public or private research centers.
L'archive ouverte pluridisciplinaire HAL, est destinée au dépôt et à la diffusion de documents scientifiques de niveau recherche, publiés ou non, émanant des établissements d'enseignement et de recherche français ou étrangers, des laboratoires publics ou privés. 


\title{
Differences in the resource intake of two sympatric Australian stingless bee species
}

\author{
Sara D. Leonhardt ${ }^{1}$, Tim A. Heard ${ }^{2}$, Helen Wallace $^{3}$ \\ ${ }^{1}$ Department of Animal Ecology and Tropical Biology, University of Würzburg, 97074, Würzburg, Germany \\ ${ }^{2}$ CSIRO Ecosystem Sciences, GPO Box 2583, Brisbane 4001, Australia \\ ${ }^{3}$ Faculty of Science, Health, Education and Engineering, University of the Sunshine Coast, Maroochydore DC \\ 4558, Australia
}

Received 22 May 2013 - Revised 3 December 2013 - Accepted 26 December 2013

\begin{abstract}
Tetragonula carbonaria and Austroplebeia australis are two species of eusocial stingless bees with phylogeographically different origins that can occur sympatrically on the Australian east coast. We studied their foraging activity and resource intake and found pronounced differences between species. Tetragonula carbonaria showed consistently higher flight activity (resulting in a higher sugar intake per minute) and thus likely collected more resin and more pollen from a broader plant spectrum than A. australis. In contrast, the smaller A. australis colonies tended to collect a narrower resource spectrum and focused on high-quality resources (i.e., nectar of significantly higher sugar concentrations). Tetragonula carbonaria colonies also gained more weight over the study period than A. australis colonies, but colony growth may nevertheless be similar between the two species, albeit resulting from differences in resource allocation and exploitation as well as worker lifespan. Given their overlapping geographic ranges, T. carbonaria and A. australis may have evolved different patterns with regard to the use of resources to avoid exploitative competition between species or due to constraints imposed by their different phylogeographic origins.
\end{abstract}

Apidae / Meliponini / foraging / plant resources

\section{INTRODUCTION}

Many related species inhabit the same habitat and thus face similar environmental challenges. Ecological niche theory predicts that, if resources are limited, natural selection may generate differences in resource exploitation in order to avoid exploitative competition among sympatric species using similar resources (Begon et al. 1990). Floral resources (i.e., pollen and nectar) are collected and used by many different insect species, and particularly bees, which entirely depend on floral resources

Corresponding author: S. D. Leonhardt, sara.leonhardt@uni-wuerzburg.de Manuscript editor: James Nieh for growth and reproduction (Michener 2007). Consequently, different bee species do frequently collect and potentially compete for resources from the same plant species.

Stingless bees (Apidae: Meliponini) are a highly social and diverse group, found exclusively in tropical and subtropical regions (Michener 1979). They are generalist foragers and visit a broad range of plant species that frequently overlap among different bee species (Engel and Dingemansbakels 1980; Sommeijer et al. 1983; Ramalho et al. 1994), although the relative importance of plants in the spectra visited may vary and was suggested to be correlated with a species' population size (Sommeijer et al. 1983). Stingless bees also collect large amounts of plant resins which they use to construct and defend their nests (Howard 1985; Roubik 1989, 2006; 
Leonhardt and Blüthgen 2009; Wallace and Lee 2010). Both floral resources (Hubbell and Johnson 1977; Eltz et al. 2002) and resin (Howard 1985) were suggested to limit colony growth and thus the population densities of stingless bees, likely resulting in competition within and among species (Johnson and Hubbell 1975; Hubbell and Johnson 1978). To avoid competition, different species seem to employ different foraging strategies with regard to recruitment ability (solitary or group foraging), the degree of local enhancement towards foragers from different species (attraction or avoidance) and competitive ability (aggressive or not), which has been shown for stingless bee species in South and Central America (Johnson 1983; Biesmeijer et al. 1999; Biesmeijer and Slaa 2004, 2006). Such species-specific foraging patterns likely result in interspecific differences in resource intake. Comparative studies on resource intake at nest entrances of stingless bee colonies are however still sparse. Yet, such colony-based studies provide a clearer picture on the actual resource intake and foraging activity of a colony as well as on colony-specific variation as foragers from different colonies can actually be differentiated. Moreover, the foraging behavior of stingless bees was studied mainly in the New World (South and Central America) which has the highest diversity of stingless bee species and genera worldwide (Michener 2007). In contrast, only two stingless bee genera, Austroplebeia and Tetragonula, reached the isolated mainland of Australia. They have very different phylogeographic origins. Austroplebeia (c. five species) is endemic to Australia and Papua New Guinea and genetically more closely related to stingless bee lineages from Africa (Rasmussen and Cameron 2010). The genus Tetragonula has around seven species in Australia and its closest relatives are found in Southeast Asia (Rasmussen and Cameron 2010). In Australia, most species inhabit the tropical North, but a few species spread to the subtropical South (Dollin et al. 1997, 2009; Walker 2010). Two of those species are Tetragonula carbonaria Smith and Austroplebeia australis Friese, the ranges of which overlap broadly (Dollin et al. 2009; Walker 2010). The two species look alike as both are black and the worker body size is 3-4.5 mm (Dollin et al. 2009; Walker 2010), but they differ in their morphology and nest architecture (Michener 2007).

We analyzed differences in resource intake and foraging activity of $T$. carbonaria and A. australis by recording the resource intake of four colonies per species that were all kept in nest boxes and located at the same site within their natural distribution in southern Queensland. Given the overlapping geographic ranges and the different phylogeographic background of the two species, we expected to find overlapping resource use, but differences in resource intake between the two species, with differences being expressed in foraging activity and specificity (i.e., variability among and within resources collected).

\section{METHODS}

\subsection{Study site and species}

The first set of observations on foraging behavior took place at the Glenmount Research Station in Buderim (South East Queensland, Australia) in March 2012. The study site is in a humid subtropical climate with warm wet summers (DecemberFebruary) and cool dry winters. We repeated our observations in January 2013 and between the end of February and mid of March 2013, as flowering and hence the availability of floral resources can differ between years and definitely differs between the peak of summer (January) and March. Consequently, all colonies were monitored in the season of highest temperatures and hence theoretically highest activity as activity tends to correlate with temperature (Heard and Hendrikz 1993; Halcroft 2012). Colonies had access to the same currently available resource environment and faced the same ecological conditions. Their foraging range (approximately 500-m radius of the hive) included a mixed rainforest and eucalypt forest as well as gardens. The floral resources from both the gardens and flowering eucalypts in the forest were abundant, especially in March.

Four colonies of $T$. carbonaria and four colonies of A. australis were observed. All four colonies of a species were approximately equal in size as estimated 
by their weight. The net weights of the colonies were normal for these species being 2-4 $\mathrm{kg}$ for $T$. carbonaria and 1-3 $\mathrm{kg}$ for A. australis. Colonies were housed in wooden nest boxes of a standard Australian design of approximately $7 \mathrm{~L}$ volume (Heard and Dollin 2000) installed under the station's roof to protect them against precipitation and direct insolation. They were placed at least $3 \mathrm{~m}$ apart and had been moved into these positions at least 30 days before the start of the trials in 2012 .

\subsection{Foraging observations}

Foraging activity and resource intake of each colony were monitored for 5-6 non-rainy days, with observations of 20-30 min taking place three times in the morning ( $7 \mathrm{AM}$ to 12 midday) and three times in the afternoon (12 midday to 6 PM) in 2012. In 2013, we confined our observations to the morning hours. Prior to each observation, we recorded the nest's foraging activity ( $A$, i.e., the number of foragers returning per minute) by counting incoming bees for 2 min. Between 10 and 20 returning foragers were then caught at the colonies' nest entrances using an insect net. For each forager, we assessed whether it carried pollen, nectar, resin or nothing to assess the relative effort allocated to a given resource (i.e., forager proportion) by each colony. All foragers captured were kept in a plastic container until the end of the observation period and released thereafter to avoid recapturing of the same individual.

To illustrate the overall intake of resources for each colony, the total number of successful foragers returning per minute with pollen, nectar and resin was estimated for each observation:

$A \times P$,

where $A$ is the activity [returning foragers/min] of this colony and $P$ the proportion of foragers that carried a particular resource.

SDL further visually assessed and recorded the color for pollen loads. Previous studies have shown that color diversity of pollen or resin loads can be used as a proxy for the diversity of plant species that the bees had visited (resin: Leonhardt et al. 2011a; pollen: Leonhardt and Blüthgen 2012). To quantify and qualify a forager's nectar load, its abdomen was squeezed slightly in order to provoke regurgitation of the crop content. Regurgitated nectar was collected with a $5-\mu \mathrm{L}$ microcapillary tube (Camag, Muttenz, Switzerland), the volume noted and the sugar concentrations measured to the nearest $0.5 \mathrm{~g} / \mathrm{g}$ sucrose equivalent using a handheld refractometer corrected for temperature (Eclipse, Bellingham \& Stanley, Kent, UK). Sugar concentration (c in \%) was converted into $x$ (in $\mu \mathrm{g} / \mu \mathrm{L}$ ) following Kearns and Inouye (1993) with the values adjusted by Blüthgen according to the following equation:

$$
\begin{aligned}
x=-0.0928 & +10.0131 \times c+0.0363 \times c^{2} \\
& +0.0002 \times c^{3} .
\end{aligned}
$$

This value was subsequently calculated into milligram based on the amount of nectar carried by each forager. We then calculated the average sugar intake (in $\mathrm{mg}$ ) per minute for each colony:

$$
\frac{\sum_{1}^{n} x \times A \times P_{N}}{n}
$$

where $n$ is the overall number of observations for a given colony, $A$ the activity of this colony at a given observation, and $P_{N}$ the proportion of nectar foragers for this observation.

In 2013, we further recorded the ambient temperature and relative humidity before and after each observation to test whether foraging activity was related to either one of these climate variables. We also weighed all eight colonies, once in January and once at the end of March 2013, to assess their weight change and hence colony growth in the summer.

We used generalized linear mixed-effect models (GLMM) with different error distributions to test for effects of species, season (i.e., peak (January) and end (March) of summer) and time of day on our different foraging response variables. In a set of preliminary tests, year explained a significant proportion of the overall variance in all models applied. We therefore decided to perform separate models for each year instead of including year as an additional variable. We tested for effects of species, season (only in 2013) and time of day (only in 2012) on the proportion of pollen, nectar and resin foragers (entered as a binomial vector, i.e., a two-column 
matrix with the columns giving the numbers of successes, e.g., the number of pollen foragers, and failures, e.g., number of non-pollen foragers) using GLMMs with a binomial error distribution (Bates et al. 2013). As we collected data from several colonies and colony was nested in species, colony was entered as a random effect in all models. Data for activity, sugar concentration, sugar intake per minute and sugar amount per forager were compared between species and seasons (in 2013) using GLMMs with Gaussian distributions. Temperature and humidity were highly negatively correlated in 2013 (Pearson's product-moment correlation: $r=-0.42, P<0.001$ ). We therefore only included temperature as additional variable in the model analyzing differences in activity in 2013. To test for seasonal differences in sugar concentration, sugar amount and sugar intake per minute in 2013, we additionally performed Student's $t$-tests for each species separately. Data for activity, sugar intake per minute and sugar amount were square root transformed and data for concentration of nectar arcsine square root transformed to meet the assumptions of normality and homogeneity of variances. Pollen specificity was assessed by calculating the Shannon diversity index based on pollen colors collected by each colony during one observation period and compared between species using Student's $t$-test. We additionally calculated the coefficients of variation (CV) for foraging activity, sugar concentration and sugar intake per minute for each species and colony to describe foraging specificity. We finally compared actual colony weight change and relative weight change between $A$. australis and $T$. carbonaria using a Student's $t$-test and Wilcoxon rank sum test, respectively.

All statistical analyses were performed in R ( $R$ Development Core Team 2013).

\section{RESULTS}

\subsection{Foraging observations}

\subsubsection{Forager proportions and numbers}

Tetragonula carbonaria colonies had an overall higher activity and hence higher numbers of foragers collecting resources than A. australis colonies (e.g., pollen and resin), in both years
(GLMM: 2012: $\chi^{2}=10.29, P=0.001 ; 2013: \chi^{2}=$ 22.79, $P<0.001$, Fig. 1 g, h, k, 1 and 2). In 2013, variation in foraging activity was further affected by season $\left(\chi^{2}=8.73, P=0.003\right)$ and an interaction between species and temperature $\left(\chi^{2}=8.96, P=0.003\right)$. Over the 2013 study period, temperature varied between 23.1 and $34.8{ }^{\circ} \mathrm{C}$ (average: $28.4{ }^{\circ} \mathrm{C}$ ), and humidity between 39.1 and $97.1 \%(63.6 \%)$. Foraging activity of $T$. carbonaria was not affected by ambient temperature (Pearson's product-moment correlation: $r=-0.08, P=0.63)$ or by relative humidity ( $r=-0.01, P=0.94)$, but foraging activity of $A$. australis increased with temperature $(r=0.30, P<$ $0.001)$ and decreased with relative humidity $(r=-0.54, P=0.05)$.

Moreover, a higher proportion of $T$. carbonaria foragers collected resin compared to A. australis, in both years (Table I, Fig. 1ad), whereas the two species did not differ in the proportion of foragers carrying pollen or nectar (Table I, Fig.1e, f, i, j).

The proportions of pollen and resin foragers in 2013 and of pollen foragers in 2012 varied among different colonies (Table I). In contrast, the different colonies showed similar nectar intake (Table I), and both species had significantly higher proportions of nectar foragers in the afternoon than in the morning (Table I).

In 2013, pollen and nectar foraging further differed between the peak of summer and March (Table I). T. carbonaria made less pollen foraging trips in the peak of summer (proportion: $0.09 \pm$ 0.08 ; forager numbers/min: $3 \pm 3$ ) than in March $(0.31 \pm 0.24 ; 18 \pm 18)$, while the number of nectar foragers per minute was similar between seasons despite differences in forager proportions (peak summer: $0.57 \pm 0.16 ; 18 \pm 10$; March: $0.31 \pm 0.17$; $21 \pm 21)$. In contrast, $A$. australis had more pollen $(0.30 \pm 0.29 ; 2 \pm 2)$ and less nectar $(0.32 \pm 0.20 ; 3 \pm$

3 ) foragers per minute in the peak of summer compared to March (pollen: $0.18 \pm 0.22 ; 1 \pm 2$; nectar: $0.51 \pm 0.24 ; 6 \pm 11)$.

\subsubsection{Nectar foraging}

The amount of nectar sugar carried by returning foragers was similar in the two species 

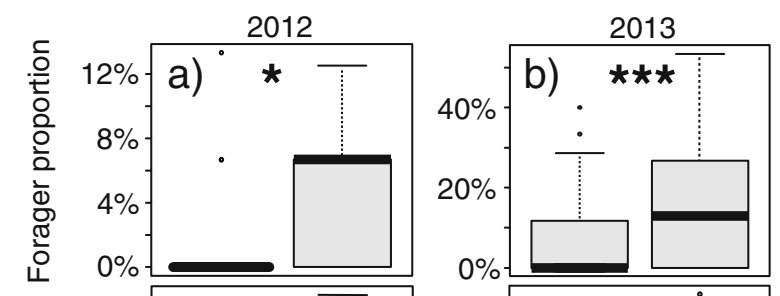

\section{蛋}
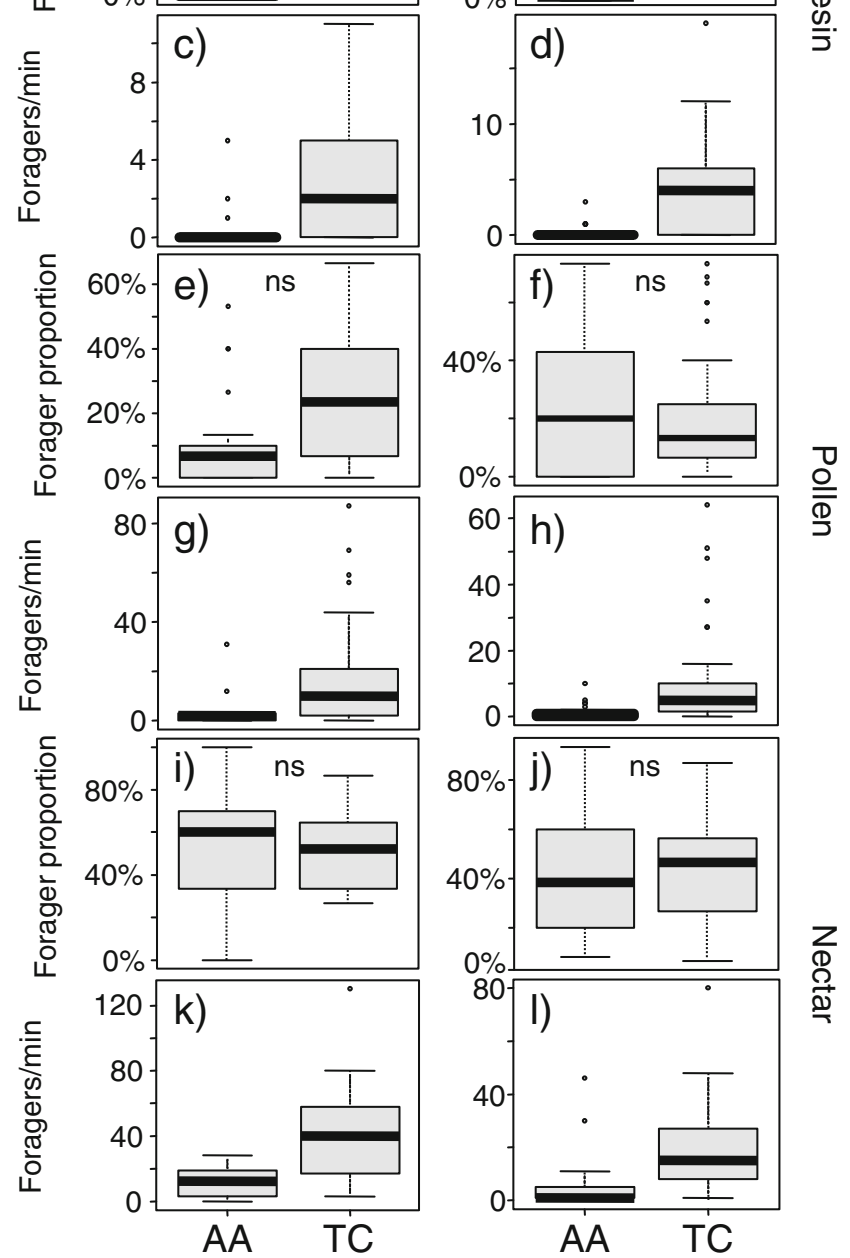

Figure 1. Proportion and estimated numbers per minutes of Tetragonula carbonaria (TC) and Austroplebeia australis (AA) foragers returning to their colonies with resin (a-d), pollen $(\mathbf{e}-\mathbf{h})$ and nectar (i-l) loads in 2012 and 2013; numbers of observations for each year and species are provided in Table II. Note that $y$-axes dimensions differ between graphs for a better illustration of results.

in both years (Tables II and III), but A. australis collected nectar with a significantly higher concentration in 2012 (Table III). However, the average sugar intake per minute was higher in $T$. carbonaria than in A. australis in both years (Tables II and III), because of T. carbonaria's higher overall foraging activity (Table II, Fig. 2). 

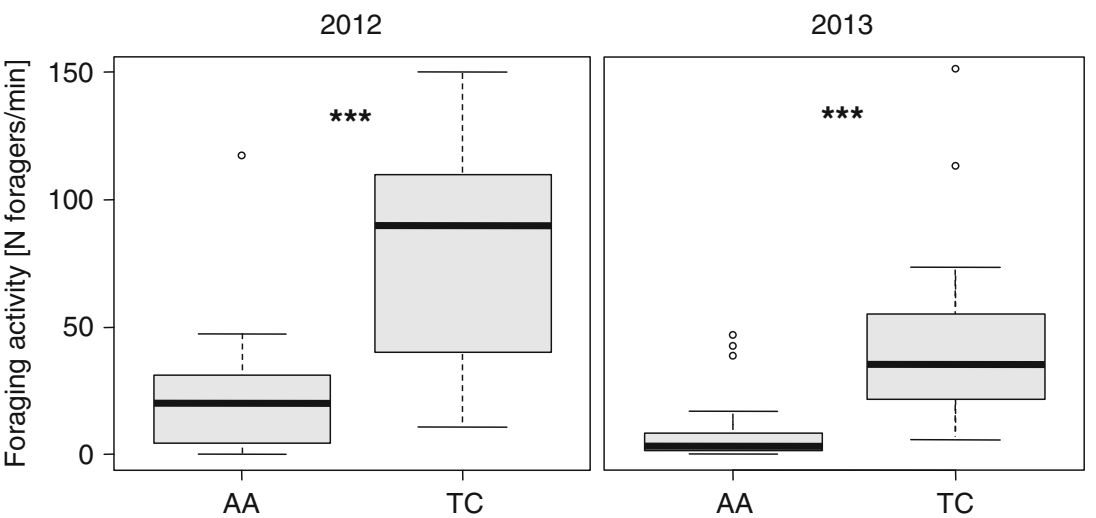

Figure 2. Foraging activity of Tetragonula carbonaria (TC) and Austroplebeia australis (AA) foragers in 2012 (a) and 2013 (b); numbers of observations for each year and species are provided in Table II. Here and in the following figures: boxplots display the median (thick bar), lower (0.25) and upper (0.75) quartile (gray box), minimum and maximum values (whiskers) and outliers of each dataset; significance levels as follows: ${ }^{*} P<$ $0.05, * * P<0.01, * * * P<0.001, n s=$ not significant.

In 2013, both species collected nectar with a higher sugar concentration in March compared to January (Table III, Fig. 3a, b). The amount of sugar in nectar carried by an individual forager did not differ between January and March in $T$. carbonaria (Table III, Fig. 3c), whereas $A$. australis collected nectar of a higher sugar quantity in March (Table III, Fig. 3d). However, overall sugar intake per minute remained relatively constant across seasons in both species (Fig. 3e, f), although season significantly contributed to the overall variance in our model (Table III).

\subsubsection{Variability in foraging activity and resource intake}

A. australis generally showed more variability in foraging activity than T. carbonaria (see CV column for activity in Table II). However, A. australis was less variable in the sugar concentration and sugar amount of nectar collected in both years as well as in sugar intake per minute in 2012 than T. carbonaria (Table II). In 2013, variability in sugar intake per minute was higher in $A$. australis than in $T$. carbonaria (Table II).
In 2012, the two species differed strongly in the number and hence diversity of pollen colors collected, with $T$. carbonaria visiting significantly more species for pollen collection (four to eight different pollen colors; average Shannon diversity across the four colonies: $1.27 \pm 0.58)$ than $A$. australis $(1-2 ; 0.25 \pm 0.20)$ $(t=-3.35, P=0.03$, Fig. 4a). A similar pattern was found in March 2013 (T. carbonaria: 6-9; $1.58 \pm 0.23 ;$ A. australis: $2-5 ; 1.00 \pm 0.39 ; t=$ $-2.71, P=0.04)$. However, overall pollen color diversity did not differ between the two species in 2013 (T. carbonaria: 6-10;1.74 $\pm 0.22 ; A$. australis: $3-10 ; 1.45 \pm 0.35 ; t=-1.39, P=0.22$, Fig. $4 b$ ), because of similar pollen intake between the two species in January ( $T$. carbonaria: $2-5 ; 1.04 \pm 0.29 ;$ A australis: $2-8$; $1.09 \pm 0.33 ; t=0.22, P=0.83)$.

\subsubsection{Colony weight gain}

Between January and March 2013, the four $T$. carbonaria colonies $(0.75 \pm 0.42 \mathrm{~kg})$ gained significantly more weight than the four $A$. australis colonies $(0.20 \pm 0.14 \mathrm{~kg} ; t=2.48, P=$ $0.04)$. Likewise, relative weight gain was significantly higher in $T$. carbonaria $(0.14 \pm$ 
Table I. Statistical results of generalized linear mixed-effect models (GLMMs) analyzing the effect of bee species, time of day (2012), season (2013) and their interactions on the proportions of resin, pollen and nectar foragers, with partial correlation coefficients (obtained from models with all variables and interactions included), residual deviances (chi-square value, $\chi^{2}$ ) and $p$-values $(P)$ displayed for fixed factors and the unconditional variances (Variance) displayed for the random factor colony.

\begin{tabular}{|c|c|c|c|c|c|c|}
\hline & & Factor & Coefficients & $\chi^{2}$ & $P$ & Variance \\
\hline \multirow[t]{12}{*}{2012} & \multirow[t]{4}{*}{ Resin } & species & 0.38 & 3.90 & 0.048 & - \\
\hline & & time of day & -17.50 & 0.01 & 0.939 & - \\
\hline & & species:time of day & 17.89 & 4.50 & 0.034 & - \\
\hline & & colony & - & - & - & $<0.001$ \\
\hline & \multirow[t]{4}{*}{ Pollen } & species & 0.56 & 1.87 & 0.172 & - \\
\hline & & time of day & 0.23 & 2.05 & 0.152 & - \\
\hline & & species:time of day & 0.14 & 0.08 & 0.774 & - \\
\hline & & colony & - & - & - & 0.228 \\
\hline & \multirow[t]{4}{*}{ Nectar } & species & -0.07 & 0.01 & 0.932 & - \\
\hline & & time of day & 0.25 & 5.22 & 0.022 & - \\
\hline & & species:time of day & -0.28 & 0.58 & 0.447 & - \\
\hline & & colony & - & - & - & 0.079 \\
\hline \multirow[t]{12}{*}{2013} & \multirow[t]{4}{*}{ Resin } & species & 1.12 & 6.65 & 0.010 & - \\
\hline & & season & 0.12 & 0.01 & 0.908 & - \\
\hline & & species:season & -0.15 & 0.12 & 0.730 & - \\
\hline & & colony & - & - & - & 0.112 \\
\hline & \multirow[t]{4}{*}{ Pollen } & species & -1.18 & $<0.01$ & 0.979 & - \\
\hline & & season & -0.54 & 11.58 & 0.001 & - \\
\hline & & species:season & 2.10 & 44.90 & $<0.001$ & - \\
\hline & & colony & - & - & - & 0.543 \\
\hline & \multirow[t]{4}{*}{ Nectar } & species & 1.00 & 0.38 & 0.540 & - \\
\hline & & season & 0.80 & 2.27 & 0.132 & - \\
\hline & & species:season & -1.87 & 59.88 & $<0.001$ & - \\
\hline & & colony & - & - & - & 0.023 \\
\hline
\end{tabular}

Bold values mark significant $p$-values

$0.09)$ than in $A$. australis $(0.02 \pm 0.02, U=16$, $P=0.03)$.

\section{DISCUSSION}

\subsection{Species-specific differences in resource intake}

The two species of the highly social stingless bees, Tetragonula carbonaria and Austroplebeia australis, are derived from two phylogenetically distant lineages and now occupy overlapping ranges. We compared foraging activity and resource intake of overall eight colonies of these two species in summer 2012 and 2013. All colonies experienced the same site, climatic conditions and flower resources. We nevertheless found strong differences between the two species in their resource intake and foraging activity. For example, T. carbonaria colonies were consistently more active than $A$. australis colonies with more foragers leaving and entering the nests. Tetragonula carbonaria colonies typically have three to four times more foragers and generally 


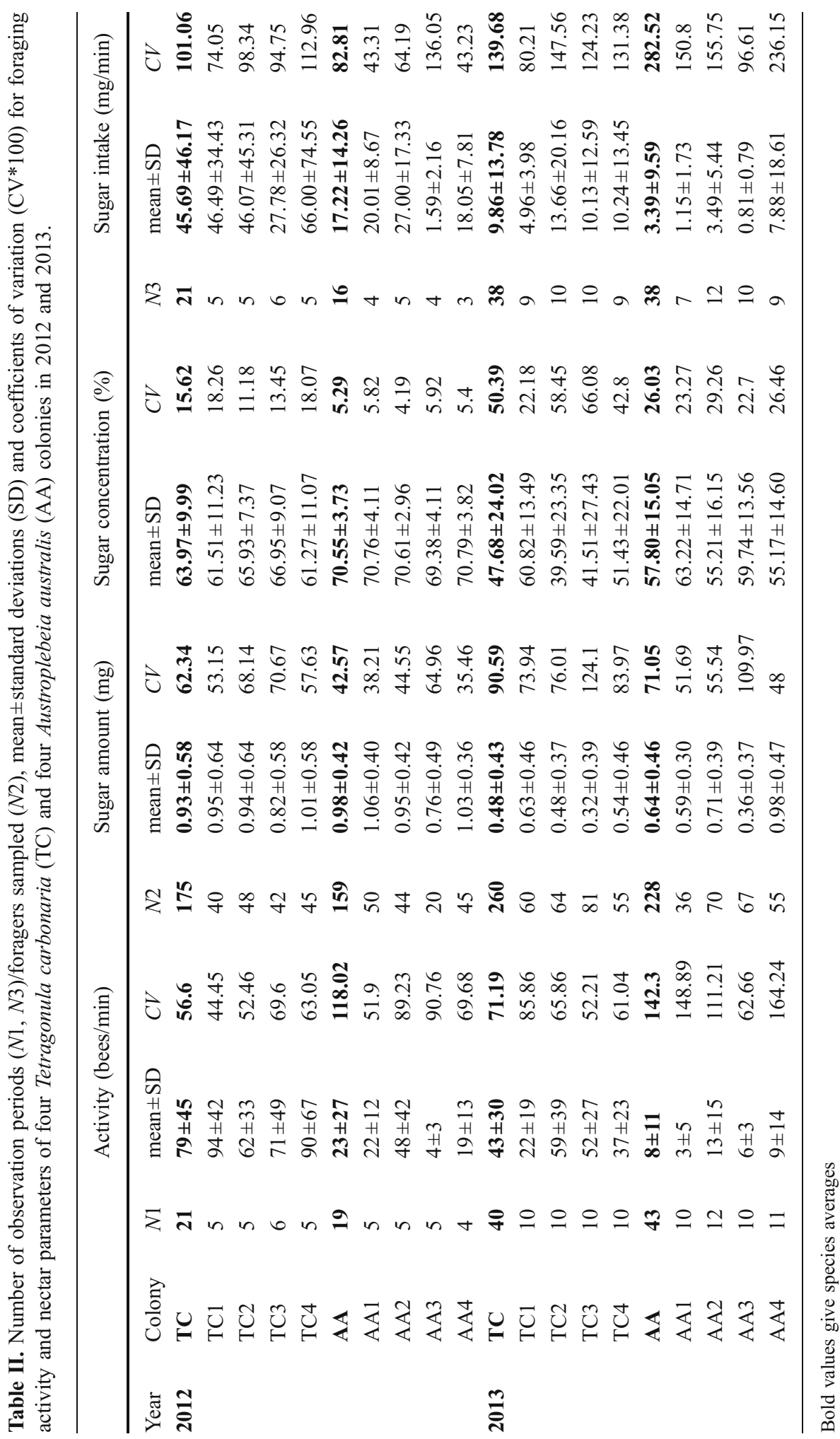


Table III. Statistical results of generalized linear mixed-effect models (GLMM) analyzing the effect of species, season and their interactions on sugar amount, concentration and intake per minute, with partial correlation coefficients (obtained from models with all variables and interactions included), residual deviances (chi-square value, $\chi^{2}$ ) and $p$-values $(P)$ displayed for fixed factors and the unconditional variances (Variance) displayed for the random factor colony.

\begin{tabular}{cllllll}
\hline & Factor & Coefficients & $\chi^{2}$ & $P$ & Variance \\
\hline 2012 & species & -0.05 & 0.77 & 0.380 & - \\
& Sugar amount & colony & - & - & - & $<0.001$ \\
& Sugar concentration & species & -0.07 & 10.73 & $\mathbf{0 . 0 0 1}$ & - \\
& colony & - & - & - & $<0.001$ \\
& species & 2.29 & 5.14 & $\mathbf{0 . 0 2 3}$ & \\
& Sugar intake/min & colony & - & - & - & $<0.001$ \\
& species & $<0.01$ & 1.29 & 0.257 & - \\
& Sugar amount & season & 0.28 & 18.29 & $<\mathbf{0 . 0 0 1}$ & - \\
& species:season & -0.22 & 6.47 & $\mathbf{0 . 0 1 1}$ & - \\
& colony & - & - & - & 0.018 \\
& species & -0.12 & 3.81 & 0.051 & - \\
& Sugar concentration & season & 0.15 & 110.19 & $<\mathbf{0 . 0 0 1}$ & - \\
& species:season & 0.12 & 8.96 & $\mathbf{0 . 0 0 3}$ & - \\
& colony & - & - & - & 0.011 \\
& Sugar intake/min & species & 1.59 & 11.51 & $<\mathbf{0 . 0 0 1}$ & - \\
& season & 0.80 & 3.92 & $\mathbf{0 . 0 4 8}$ & - \\
& species:season & -0.26 & 0.15 & 0.697 & - \\
& colony & - & - & - & $<0.001$ \\
\hline & & & &
\end{tabular}

Bold values mark significant $p$-values

larger colonies than A. australis (Halcroft 2012) which may explain the differences in foraging activity between the two species. However, Halcroft (2012), who found similar activity patterns for the two species as we found in our study, pointed out that foraging activity was occasionally nine- to 40 -fold higher in $T$. carbonaria compared to A. australis, and hence exceeded differences that could be explained by differences in colony size alone. Instead, she suggested that the two species applied different foraging strategies (Halcroft 2012).

The higher foraging activity of $T$. carbonaria resulted in greater resource collection, e.g., a significantly higher sugar intake per minute. Moreover, T. carbonaria likely collected more pollen and resin, as inferred from their higher foraging activity and from larger forager proportions and given that pollen and resin loads of the two species are similar in size (personal observation). This comparatively higher resource intake may explain why $T$. carbonaria colonies gained weight faster than $\operatorname{did} A$. australis colonies.

Note that foraging activity varied between colonies of the same species, likely due to differences in their internal states (i.e., food storage or number of offspring currently raised), which can affect forager numbers (e.g., pollen storage: Pernal and Currie 2001).

Overall variation in foraging activity was more pronounced in A. australis than in $T$. carbonaria. Moreover, foraging activity in $A$. australis increased with increasing temperatures and decreasing humidity, which agrees with Halcroft (2012). Foraging activity of $T$. carbonaria did not correlate either with relative humidity or temperature, likely because temper- 

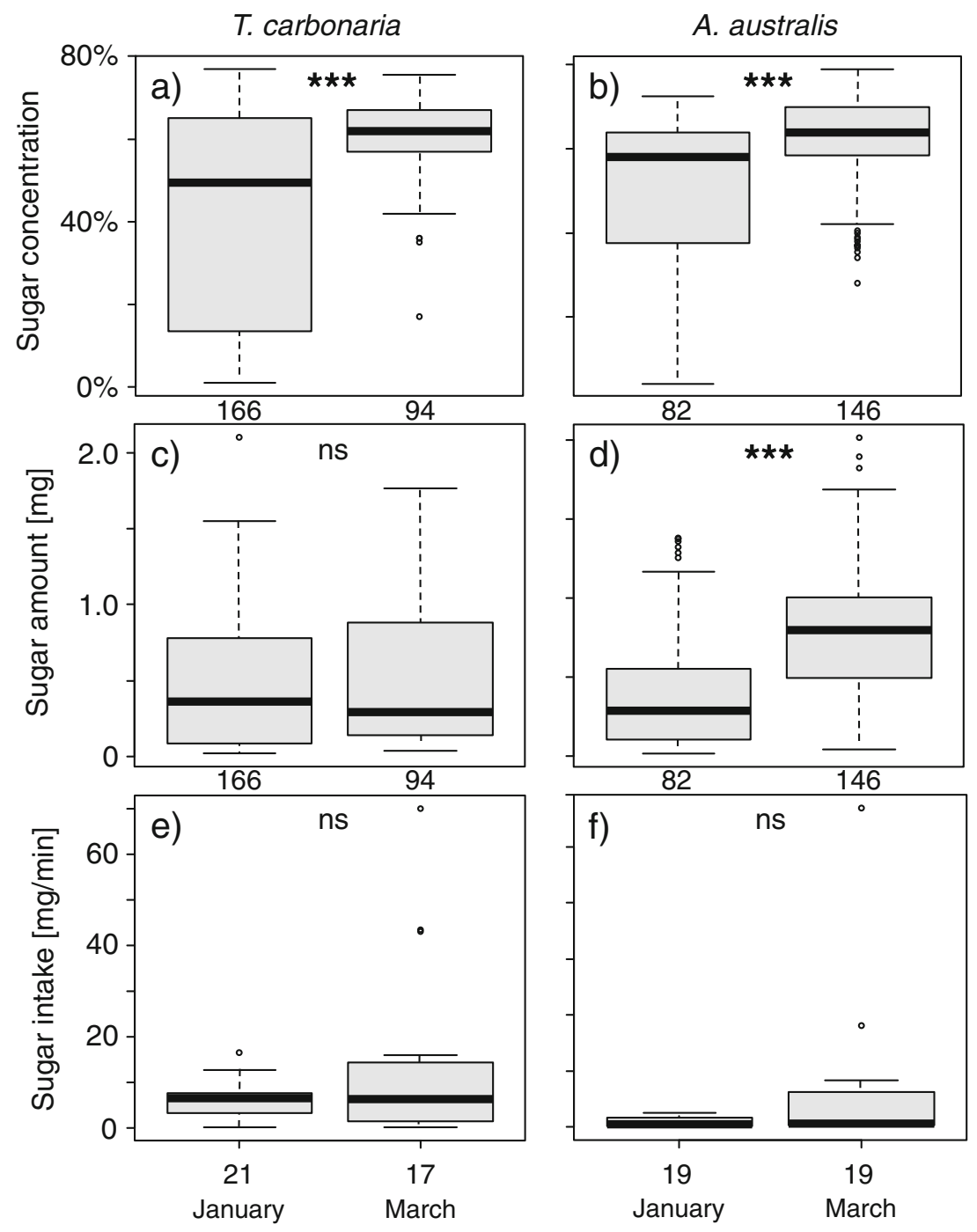

Figure 3. Sugar concentration (a, b), sugar amount per individual forager $(\mathbf{c}, \mathbf{d})$ and sugar intake per minute (e, f) in Tetragonula carbonaria and Austroplebeia australis in January and March 2013; numbers below graphs give sample sizes for each measurement.

atures never fell below $23{ }^{\circ} \mathrm{C}$ in our study period. Heard and Hendrikz (1993) found that $T$. carbonaria started foraging when temperatures rose above $18{ }^{\circ} \mathrm{C}$, and that activity increased linearly with temperature above this threshold (Heard and Hendrikz 1993). The temperature threshold at which $A$. australis starts foraging is $20{ }^{\circ} \mathrm{C}$ (Halcroft 2012). A. australis colonies may thus have similar high activities as well as a similar pollen and sugar intake as $T$. carbonaria colonies in areas that are warmer and drier than our study area.

The two species further differed strongly in the relative proportion of resin foragers, with $A$. australis colonies collecting only very little to no resin and up to $50 \%$ of $T$. carbonaria foragers collecting resin. Our findings for $T$. carbonaria support previous studies on resin collection in 


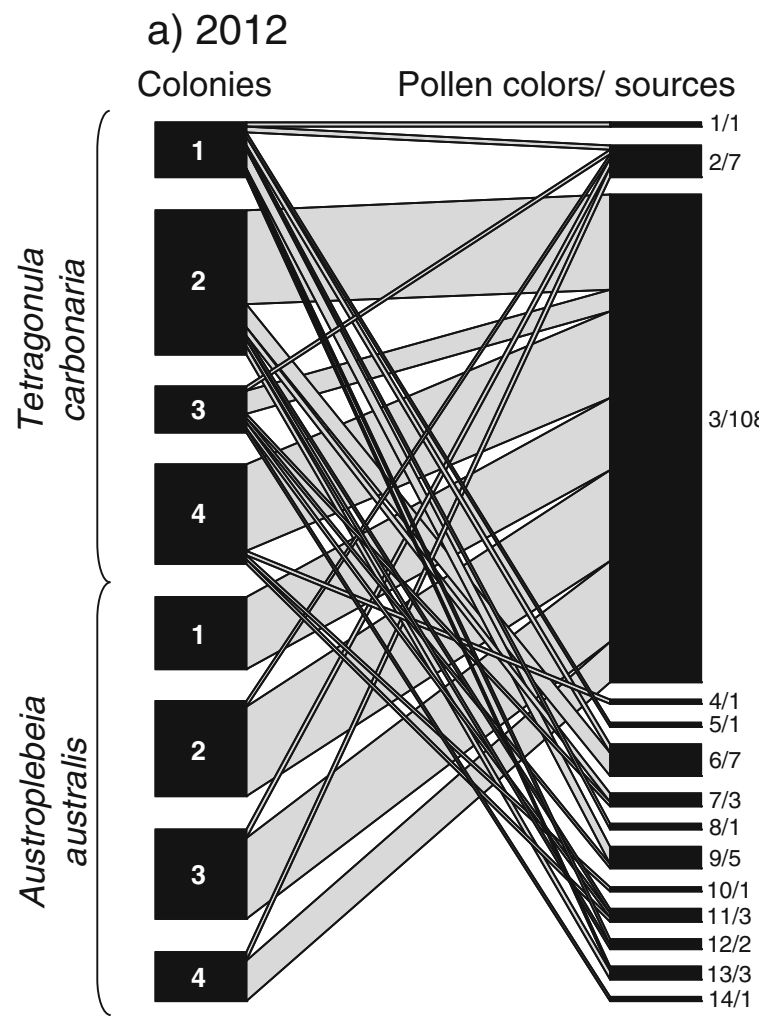

b) 2013

Colonies Pollen colors/ sources

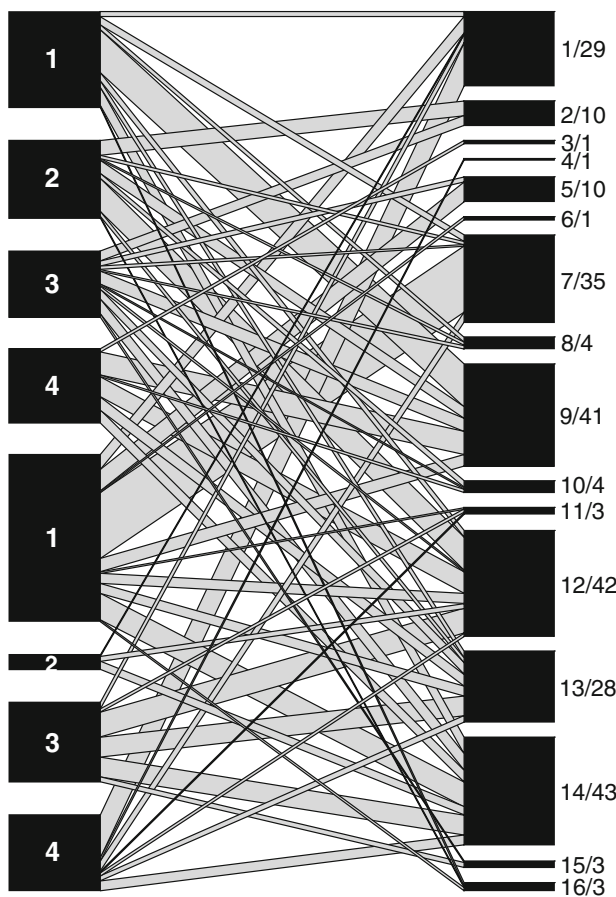

Figure 4. Foraging networks showing our four Tetragonula carbonaria and four Austroplebeia australis colonies (left) collecting different pollen colors/sources (right) in 2012 and 2013; numbers behind pollen color/ source numbers give total numbers of pollen loads collected from foragers for this particular color. Colors/ sources were pooled for all observations throughout each study period. Lines between a colony and pollen colors show the pollen types collected by that colony with line width correlating with the amount of pollen collected from this particular pollen type. Bar width correlates with the number of pollen foragers per colony in relation to pollen foragers of all colonies (left), or with the proportion of each pollen color of all colors collected (right), respectively. Note that the same pollen color numbers do not represent the same pollen color in 2012 and 2013

other Tetragonula species (Inoue et al. 1985; Wallace and Trueman 1995; Wallace et al. 2008; Leonhardt and Blüthgen 2009). The difference in resin intake between the two species may result from different needs for resin. Notably, both bee genera store resin in their nest which they use to defend their colonies against intruders - such as ants (Tetragonula: Leonhardt and Blüthgen 2009) or the small hive beetle, Aethina tumida (Tetragonula: Greco et al. 2010; Austroplebeia: Halcroft 2012). However, T. carbonaria uses resin to build nest structures and mark the nest entrance (personal observation), whereas A. australis does not include resin in its nest material (Milborrow et al. 1987; Drescher N, Wallace H, Schmitt T and Leonhardt SD, unpublished data). Moreover, $T$. carbonaria bees transfer compounds from resin to their body surface (Leonhardt et al. 2011b) which enrich their cuticular profile and protect them against predators (Wenzel 2011), a strategy that is not seen in A. australis (Leonhardt et al. 2011b; Wenzel 2011). Consequently, T. carbonaria most likely has a more pronounced need for resin which is expressed in a higher resin intake.

The diversity of pollen collected also differed between the two species in 2012, with a higher 
proportion of $T$. carbonaria foragers collecting pollen from more pollen sources. The higher pollen color diversity collected by $T$. carbonaria cannot simply be explained by its higher foraging activity, as pollen color diversity was not correlated with foraging activity $(r=-0.01$, $P=0.96$ ). However, in $2013, T$. carbonaria collected a higher diversity of pollen (colors) only in March, whereas both species collected from at least five different plant species in January. Note that diversity based on pollen color underestimates the actual diversity of plants visited for pollen collection due to partly similar pollen colors of some plant species, but it reliably describes trends (Leonhardt and Blüthgen 2012). It is thus possible that $A$. australis collects pollen from a narrower flower spectrum than $T$. carbonaria, at least in periods of intense flowering, whereas $T$. carbonaria may be the more generalist and opportunistic pollen forager. The differences in pollen color spectra collected may result from speciesspecific differences in floral preferences as has also been suggested for stingless bees in Borneo (Eltz et al. 2001). Similar to bumblebees in temperate regions (Leonhardt and Blüthgen 2012), A. australis might focus more specifically on resources of high quality, if they are available. In contrast, $T$. carbonaria seems to be less specific in its foraging choices, collecting overall more resources of potentially both high and low quality. This assumption is supported by the equally narrow spectrum of nectar concentrations measured for crop contents of A. australis, in contrast to T. carbonaria that collected more nectar of lower concentrations. This finding indicates that $A$. australis specifically foraged on floral sources with highly concentrated nectar and hence a higher sugar content and thus higher caloric value, and suggests that, even among floral generalists, different species may compose different diets according to different caloric strategies.

The differences in resource intake between the two study species may reflect competition avoidance or displacement interactions that restrict access to certain resources. Moreover, interspecific interactions are known to alter locations where stingless bees collect resources (Johnson 1974, 1983; Nagamitsu and Inoue 1997; Lichtenberg et al. 2010). A prerequisite for a change in behavior in animals that aims to avoid competition is that resources are limited (Begon et al. 1990). But whether floral resources are limiting for bees in Australia is unknown. Eucalypts (Myrtaceae) are the dominant tree species in the natural environment of T. carbonaria and A. australis. Many Myrtaceae species are adapted for bird pollination and produce large floral displays with nectar of high caloric value (Ford et al. 1979; Beardsell et al. 1993). Bees may only consume a small proportion of those resources. Hence, competition among bees for floral resources may be less fierce in Australia than it is in other parts of the world (e.g., the Neotropics), at least during eucalypt flowering. This hypothesis is supported by observations of Halcroft (2012) who did not observe any aggressive encounters between foragers of the two species collecting pollen and nectar from greenhouse plants. Moreover, whereas $T$. carbonaria is known to quickly recruit foragers to and potentially monopolize resources (Bartareau 1996), nothing is known about the efficiency in recruiting nestmates and exploiting resources in A. australis. The narrow pollen and nectar concentration spectra collected by the latter may suggest that they also focus on few resources of potentially high quality. Like some species in the Neotropics (Johnson 1974; Hubbell and Johnson 1978; Biesmeijer and Slaa 2004), A. australis might avoid encounters with other individuals and rely on the efficiency of individual foragers instead of recruiting large numbers of foragers to one particular resource (see also Halcroft 2012). Moreover, A. australis foragers were found to spend considerably less time hovering in front of flowers than $T$. carbonaria foragers, hence being the more effective foragers in terms of energy usage while foraging (Halcroft 2012). Alternatively, the differences in resource intake observed may be genetically and biogeographically constrained by the species' different phylogenetic and phylogeographic backgrounds. 
Our findings indicate that, according to our predictions, $A$. australis and T. carbonaria show differences in their resource use, which may result from competition avoidance or from different phylogenetic and phylogeographic origins. Colony growth and development of $A$. australis may be reduced compared to $T$. carbonaria because resource intake determines colony growth rates. However, A. australis bees do live unusually long and likely longer than $T$. carbonaria bees (Halcroft 2012) which may (partly) compensate for reduced colony growth. Moreover if $A$. australis focuses on high-quality resources instead of quantity, colony growth may be similar between the two species, albeit resulting from differences in resource allocation and exploitation. To better understand how differences in resource intake affect colony growth and development in the two study species, long-term data on the growth and development of more and also naturally occurring colonies coexisting in the same undisturbed habitat as well as more detailed analyses of the quality of resources collected are needed. In addition, comparative studies on related species of both genera will indicate whether the divergent patterns are due to phylogenetic constraints.

\section{ACKNOWLEDGMENTS}

We thank three anonymous reviewers for their valuable comments on former versions of this manuscript, as well as Henrik v. Wehrden and Lucas Garibaldi for their statistical support. Funding was provided by the Deutsche Forschungs-Gemeinschaft (DFG project: LE 2750/1-1) and by the Queensland Government NIRAP Smart Forests Alliance Queensland.

\section{Stratégies d'approvisionnement différentes chez deux espèces australiennes sympatriques d'abeilles sans aiguillon}

\section{Apidae / Meliponini / approvisionnement/ ressources végétales / Australie}

Unterschiede im Ressourceneintrag zwischen zwei in Australien sympatrisch vorkommenden

\section{Stachellose BienenartenApidae / Meliponini / Nahrungssuche / Pflanzenressourcen}

\section{REFERENCES}

Bartareau, T. (1996) Foraging behaviour of Trigona carbonaria (Hymenoptera: Apidae) at multiplechoice feeding stations. Aust. J. Zool. 44, 143-153

Bates D., Maechler M., B. Bolker, (2013). lme4: Linear mixed-effects models using S4 classes. R package version 0.999999-2.http://CRAN.R-project.org/ package $=1 \mathrm{me} 4$

Beardsell, D.V., O’Brien, S.P., Williams, E.G., Knox, R.B., Calder, D.M. (1993) Reproductive biology of Australian Myrtaceae. Aust. J. Bot. 41, 511-526

Begon, M., Harper, J.L., Townsend, C.R. (1990) Ecology: individuals, populations and communities. Blackwell Scientific Publications, Boston

Biesmeijer, J.C., Slaa, E.J. (2004) Information flow and organization of stingless bee foraging. Apidologie 35, 143-157

Biesmeijer, J.C., Slaa, E.J. (2006) The structure of eusocial bee assemblages in Brazil. Apidologie 37, 240-258

Biesmeijer, J.C., Richter, J.A.P., Smeets, M., Sommeijer, M.J. (1999) Niche differentiation in nectarcollecting stingless bees: the influence of morphology, floral choice and interference competition. Ecol. Entomol. 24, 380-388

R Development Core Team, (2013) R: a language and environment for statistical computing, URL http:// www.R-project.org, R Foundation for Statistical Computing, Vienna.

Dollin, A.E., Dollin, L.J., Sakagami, S.F. (1997) Australian stingless bees of the genus Trigona (Hymenoptera : Apidae). Invertebr. Taxon. 11, 861-896

Dollin A., K. Walker, T. Heard, (2009) "Trigona carbonaria" sugarbag bee (Tetragonula carbonaria). PaDIL - http://www.padil.gov.au2012

Eltz, T., Brühl, C.A., van der Kaars, S., Chey, V.K., Linsenmair, K.E. (2001) Pollen foraging and resource partitioning of stingless bees in relation to flowering dynamics in a Southeast Asian tropical rainforest. Insectes Soc. 48, 273-279

Eltz, T., Brühl, C.A., van der Kaars, S., Linsenmair, K.E. (2002) Determinants of stingless bee nest density in lowland dipterocarp forests of Sabah, Malaysia. Oecologia 131, 27-34

Engel, M.S., Dingemansbakels, F. (1980) Nectar and pollen resources for stingless bees (Meliponinae, Hymenoptera) in Surinam (South-America). Apidologie 11, 341-350

Ford, H.A., Paton, D.C., Forde, N. (1979) Birds as pollinators of Australian plants. New Zeal. J. Bot. 17, 509-519 
Greco, M.K., Hoffmann, D., Dollin, A., Duncan, M., Spooner-Hart, R., Neumann, P. (2010) The alternative pharaoh approach: stingless bees mummify beetle parasites alive. Naturwissenschaften . doi:10.1007/s00114-009-0631-9

Halcroft, M.T. (2012) Investigations into the biology, behaviour and phylogeny of a potential crop pollinator: the Australian stingless bee. University of Western Sydney, Austroplebeia australis. Doctor of Philosophy thesis

Heard, T.A., Dollin, A. (2000) Stingless beekeeping in Australia, snapshot of an infant industry. Bee World 82, 116-125

Heard, T.A., Hendrikz, J.K. (1993) Factors influencing flight activity of colonies of the stingless bee Trigona carbonaria (Hymenoptera, Apidae). Aust. J. Zool. 41, 343-353

Howard, J.J. (1985) Observations on resin collecting by six interacting species of stingless bees (Apidae, Meliponinae). J. Kans. Entomol. Soc. 58, 337-345

Hubbell, S.P., Johnson, L.K. (1977) Competition and nest spacing in a tropical stingless bee community. Ecology 58, 949-963

Hubbell, S.P., Johnson, L.K. (1978) Comparative foraging behavior of six stingless bee species exploiting a standardized resource. Ecology 59, 1123-1136

Inoue, T., Salmah, S., Abbas, I., Yusuf, E. (1985) Foraging behavior of individual workers and foraging dynamics of colonies of three Sumatran stingless bees. Res. Popul. Ecol. 27, 373-392

Johnson, L.K. (1974) The role of agonistic behavior in the foraging strategies of Trigona bees. University of California, Berkeley

Johnson, L.K. (1983) Foraging strategies and the structure of stingless bee communities in Costa Rica. In: Jaisson, P. (ed.) Social Insects in the Tropics 2, p. 252. Université Paris-Nord, Paris, France

Johnson, L.K., Hubbell, S.P. (1975) Contrasting foraging strategies and coexistence of two bee species on a single resource. Ecology 56, 1398-1406

Kearns, C.A., Inouye, D.W. (1993) Techniques for pollination biologists. University Press of Colorado, Niwor, Colorado, USA

Leonhardt, S.D., Blüthgen, N. (2009) A sticky affair: resin collection by Bornean stingless bees. Biotropica 41, 730-736

Leonhardt, S.D., Blüthgen, N. (2012) The same, but different: pollen foraging in honeybee and bumblebee colonies. Apidologie 43, 449-464

Leonhardt, S.D., Schmitt, T., Blüthgen, N. (2011a) Tree resin composition, collection behavior and selective filters shape chemical profiles of tropical bees (Apidae: Meliponini). Plos One 6, e23445

Leonhardt, S.D., Wallace, H.M., Schmitt, T. (2011b) The cuticular profiles of Australian stingless bees are shaped by resin of the eucalypt tree Corymbia torelliana. Austral Ecol. 36, 537-543

Lichtenberg, E.M., Imperatriz-Fonseca, V.L., Nieh, J.C. (2010) Behavioral suites mediate group-level foraging dynamics in communities of tropical stingless bees. Insectes Soc. 57, 105-113

Michener, C.D. (1979) Biogeography of the bees. Ann. Missouri Bot. Garden 66, 277-347

Michener, C.D. (2007) The bees of the world. John Hopkins University Press, Baltimore \& London

Milborrow, B.V., Kennedy, J.M., Dollin, A. (1987) Composition of wax made by the Australian stingless bee Trigona australis. Aust. J. Biol. Sci. 40, 15-25

Nagamitsu, T., Inoue, T. (1997) Aggressive foraging of social bees as a mechanism of floral resource partitioning in an Asian tropical rain. Oecologia 110, 432-439

Pernal, S.F., Currie, R.W. (2001) The influence of pollen quality on foraging behavior in honeybees (Apis mellifera L.). Behav. Ecol. Sociobiol. 51, 53-68

Ramalho, M., Giannini, T.C., Malagodibraga, K.S., Imperatriz-Fonseca, V.L. (1994) Pollen harvest by stingless bee foragers (Hymenoptera, Apidae, Meliponinae). Grana 33, 239-244

Rasmussen, C., Cameron, S.A. (2010) Global stingless bee phylogeny supports ancient divergence, vicariance, and long distance dispersal. Biol. J. Linn. Soc. 99, 206-232

Roubik, D.W. (1989) Ecology and natural history of tropical bees. Cambridge University Press, New York

Roubik, D.W. (2006) Stingless bee nesting biology. Apidologie 37, 124-143

Sommeijer, M.J., Derooy, G.A., Punt, W., Debruijn, L.L.M. (1983) A comparative study of foraging behavior and pollen resources of various stingless bees (Hym, Meliponinae) and honeybees (Hym, Apinae) in Trinidad, West-Indies. Apidologie 14, 205-224

Walker K., (2010) “Austroplebeia australis" sugarbag bee (Austroplebeia australis). PaDIL - http:// www.padil.gov.au 2012.

Wallace, H.M., Lee, D.J. (2010) Resin-foraging by colonies of Trigona sapiens and T. hockingsi (Hymenoptera: Apidae, Meliponini) and consequent seed dispersal of Corymbia torelliana (Myrtaceae). Apidologie 41, 428-435

Wallace, H.M., Trueman, S.J. (1995) Dispersal of Eucalyptus torelliana seeds by the resin-collecting stingless bee, Trigona carbonaria. Oecologia 104, 12-16

Wallace, H.M., Howell, M.G., Lee, D.J. (2008) Standard yet unusual mechanisms of long-distance dispersal: seed dispersal of Corymbia torelliana by bees. Divers. Distrib. 14, 87-94

Wenzel, F. (2011) Smell and repel: resin-based defense mechanisms and interactions between Australian ants and stingless bees, p. 77. Theodor-Boveri-Institut für Biowissenschaften, University of Würzburg, Würzburg 